\title{
Basaloid squamous cell carcinoma of uterine cervix in a young adult - A case
}

\section{report}

\section{Angel Yordanov ${ }^{1}$, Stanislav Slavchev ${ }^{2}$, Vasil Nanev ${ }^{3}$ Denislava Ivanova ${ }^{4}$, Momchil Ivanov $^{5}$, and} Strahil Strashilov 6

1. Department of Gynecologic Oncology, Medical University Pleven, Bulgaria

2. Clinic of Gynaecology, University Hospital "St. Anna"-Varna, Bulgaria

3. Department of Surgical Oncology, Medical University Pleven, Bulgaria

4. Department of Obstetrics and Gynecology, University Hospital Sofiamed, Sofia, Bulgaria

5. MHAT "Saint Paraskeva"-Pleven, Bulgaria

6. Department of Plastic Restorative, Reconstructive and Aesthetic Surgery, Medical University Pleven,

Bulgaria

\section{CASE STUDY}

Please cite this paper as: Yordanov A, Slavchev S, Nanev V, Ivanova D, Ivanov $M$, Strashilov $S$. Basaloid squamous cell carcinoma of uterine cervix in a young adult - A case report. AMJ 2019;12(12):364-367.

https://doi.org/10.35841/1836-1935.12.12.364-367

\section{Corresponding Author:}

Angel Danchev Yordanov

Clinic of Gynecologic Oncology, University Hospital "Dr. Georgi Stranski", Medical University Pleven, Georgi Kochev $8 \mathrm{~A}$, Bulgaria

Email: angel.jordanov@gmail.com

\section{ABSTRACT}

Basaloid squamous cell carcinoma of the uterine cervix is an extremely rare and aggressive malignancy. It has poorer clinical outcomes than squamous cell carcinoma of the uterine cervix. The tumour has specific microscopic features, and usually affects patients in their late 60s and 70s. We present a very rare case of a 30 -year-old woman, who was diagnosed on a prophylactic examination and was treated with radical hysterectomy and pelvic lymph node dissection. The follow-up of the patient is ongoing.

\section{Key Words}

Cervical cancer, basaloid squamous cell carcinoma, basaloid cells squamous cell carcinoma, young adult

\section{Implications for Practice:}

\section{What is known about this subject?}

This rare and aggressive tumour affects mostly patients in their late 60 s and 70 s.

\section{What new information is offered in this case study?} It is possible to occur in very young adults.

3. What are the implications for research, policy, or practice?

It is important to be differentiated from other tumours of cervix because of its different clinical behaviour and Prognosis.

\section{Background}

The term basaloid squamous cell carcinoma (BSCC) was used for the first time by Wain et al. in 1986. ${ }^{1}$ The authors described with it "a highly malignant variant of squamous cell carcinoma with a basaloid pattern" that had developed over the tongue, laryngopharynx, and larynx. A great number of cases of tumours with such morphology have been described until the present day since then. The tumour derives most often from the larynx, laryngopharynx, tonsils, and base of the tongue, and more rarely from the nose, paranasal sinuses, external ear, submandibular region, oesophagus, lung, uterine cervix, vulva, vagina, and anus. ${ }^{2,3}$ One of the rarest locations of that disease is the uterine cervix. ${ }^{4}$ It is thought that the tumour has a more aggressive course than the classical cervical squamous cell carcinoma (SCC), higher metastatic potential, and poorer prognosis. ${ }^{5}$

We present a case of a young woman with an asymptomatic course of BSCC, diagnosed on a prophylactic examination, which underwent radical surgical treatment performed 
thereafter.

\section{Case details}

This is a 30-year-old female patient (G0, P0), from whom a cytologic smear was taken on a prophylactic examination Papanicolaou test IIIB. A biopsy of the uterine cervix was performed with the following histological result: cervical intraepithelial neoplasia (CIN) III up to carcinoma of the uterine cervix in situ. The patient had thalassemia minor as a concomitant disease and did not report any surgical interventions previously performed. Conisation was performed - after standard preoperative preparation - with the following histological result: basaloid squamous cell carcinoma with deep invasion in the stroma and clean resection lines (Figure 1).

\section{Figure 1: Cervical stroma infiltrated by non-keratinizing squamous cell carcinoma with basaloid morphology HE 200x}

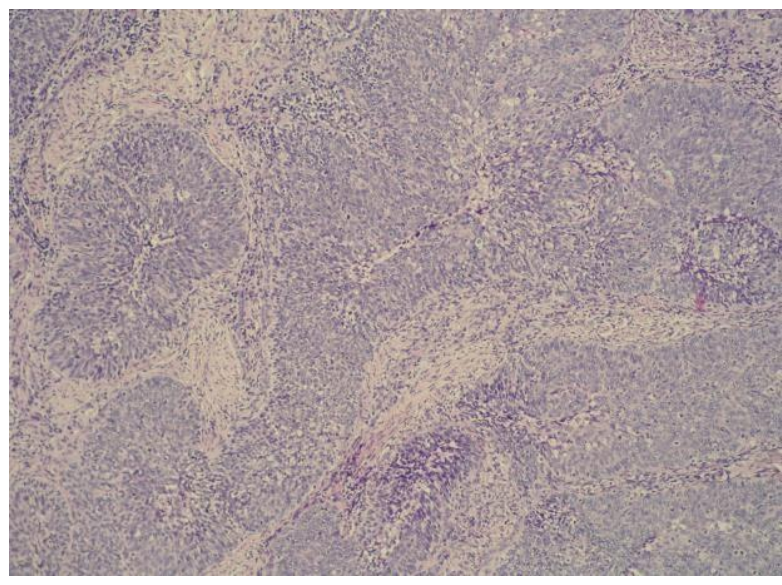

Computed axial tomography (CT) of pelvis and abdomen was implemented later, while the stage of cancer of the patient was determined as pT1b1NOMO. By the histological variant, a decision was made for performing radical hysterectomy with pelvic lymph node dissection. This surgical operation was performed one month after the conisation, while no residual tumour in the uterine cervix and no metastases in the lymph nodes were found. The patient was discharged from the hospital with no complications and was directed for performing adjuvant radiotherapy. The follow-up of the patient is ongoing.

\section{Discussion}

The classification of cancer of the uterine cervix comprises different histological types, which require different clinical behaviour. One of these types is BSCC. It is a rare variant of squamous cell carcinoma (SCC) with an aggressive course, and it affects mainly patients in their late 60 s and 70 s.
Single cases at a younger age were also described. ${ }^{2,6}$ The basaloid carcinoma has different locations: laryngopharynx, the base of the tongue, salivary glands, oesophagus, anal canal, prostate, thymus, vulva, and urinary bladder. The finding of involvement of the uterine cervix is exceptionally rare. $^{5}$ Regardless of its location; it has a specific morphological picture. It includes nests or cords of small basaloid cells, hyperchromatic epithelial cells with high nucleocytoplasmic ratios, foci of comedonecrosis, a tendency to palisade at the periphery of the tumour islands, having prominent peripheral palisading of cells in the tumour cell nests, and absence of significant stromal reaction. $^{7}$

It is regarded that BSCC is associated with human papillomavirus infection. ${ }^{8,9}$ The consumption of alcohol and smoking are predisposing factors for its development. ${ }^{2}$

The clinical picture of that disease does not differ from that of the classical SCC. It includes irregular and contacts bleeding, and a formation at the uterine cervix. The differential diagnosis must be done with the other malignant diseases of the uterine cervix as spindle cell squamous carcinoma, adenoid cystic carcinoma, adenosquamous carcinoma, cystic, small cell carcinoma, large cell neuroendocrine carcinoma of the cervix, and basosquamous cell carcinoma. ${ }^{10-13}$ The accurate diagnosis is obligatory due to the different clinical behaviour, prognosis, and therapeutic approaches in the case of this tumor. ${ }^{10}$ Some immunohistochemical (IHC) markers are used for its finding - among them: CK-AE1/AE 3, cytokeratin-7 (CK7), tyrosine-proteinkinase (C-KIT), carcinogenic embryogenic antigen (CEA), cancer antigen 19-9 (CA19-9), epithelial membrane antigen (EMA), cytokeratin-34 $\beta 12$ (CK 34BE12), p63 protein, chromogranin, synaptophysin, platelet-derived growth factor receptor (PDGFRA), oestrogen receptor (ER), cluster of differentiation-56 (CD56), and thyroid transcription factor- 1 (TTF-1). ${ }^{2,14}$ For some of them BSCC is positive, and for others - negative.

It is accepted that the aggressive behaviour of this tumour is associated with early recurrence, lymph node involvement and also distant metastasis to the liver and lung. ${ }^{15}$ It must be noted, however, that no studies are comparing stage-bystage outcome and survival in basaloid squamous cell carcinoma versus usual squamous cell carcinoma of the cervix.

In our case, a 30-year-old patient was presented, and this was the youngest age at which BSCC was described. There are data in the literature of several cases at an age younger 
than the standard for this disease. ${ }^{5,16}$ The youngest female patient with this disease found by us was 35 -year-old. ${ }^{16}$ In this case, the tumour had exceptionally rapid growth. The disease - as far as our patient is concerned - had an asymptomatic course, and the diagnosis was made by accident on a prophylactic examination. Notwithstanding that there was no data of lymphovascular invasion from the performed conisation, and there were no metastatic lymph nodes from the computed axial tomography of the abdomen and lesser pelvis, it was preceded to performing of radical hysterectomy with pelvic lymph node dissection. The patient was a nulliparous woman and the decision for such a kind of operative intervention was made with great difficulty. It was based on the carried out detailed literature reference, which showed that the tumour is very aggressive, regardless of its early stage.

\section{Conclusion}

Basaloid squamous cell carcinoma is a very rare, aggressive subtype of squamous cervical cancer and it must be differentiated from other tumours of cervix. Infrequently it may occur in young adults. It is necessary to be gathered some more information for it, as well as to be compared its clinical course with the one of conventional cervical squamous cell carcinoma of similar clinical stage. These data would help to be determined the best diagnosis and treatment options. Long-term follow-up is mandatory because of the high risk of recurrence.

\section{References}

1. Wain SL, Kier R, Vollmer RT, et al. Basaloid squamous cell carcinoma of the tongue, hypopharynx and larynx. Report of 10 cases. Hum Pathol. 1986;17:1158-66.

2. Vasudev P, Boutross-Tadross O, Radhi J. Basaloid squamous cell carcinoma: two case reports. Cases J. 2009;2:9351.

3. Wieneke JA, Thompson LD, Wenig BM. Basaloid squamous cell carcinoma of the sinonasal tract. Cancer. 1999;15:841-854.

4. Salarvand S, Haeri H, Ghalehtaki R, et al. Non-Metastatic Basaloid Squamous Cell Carcinoma of the Uterine Cervix in a Woman with History of Subtotal Hysterectomy. Int J Cancer Manag. 2017;10(6):e9301. doi: 10.5812/ijcm.9301.

5. Sharma JC, Kochar SPS, Arora D, et al. Basaloid squamous cell carcinoma of the uterine cervix: a rare aggressive variant of cervical malignancy. Asian Pac J Health Sci. 2015;2(1):125-128.

6. Morles-Puebla JM, Toro-Rojas M, Gerons RSS, et al. Basaloid squamous cell carcinoma: Report of five cases. Med Oral Patol Oral Cir Bucal. 2010;15:451-5.
7. Kwon YS, Kim YM, Choi GW, et al. Pure basaloid squamous cell carcinoma of the uterine cervix: a case report. J Korean Med Sci. 2009;24(3):542-545. doi:10.3346/jkms.2009.24.3.542

8. Cubilla AL, Reuter VE, Gregoire L, et al. Basaloid squamous cell carcinoma: a distinctive human papilloma virus-related penile neoplasm: a report of 20 cases. Am Surg Pathol. 1998;22:755-61.

9. Banks ER, Frierson HF, Jr, Mills SE, et al. Basaloid squamous cell carcinoma of the head and neck: a clinicopathologic and immunohistochemical study of 40 cases. Am J Surg Pathol. 1992;16:939-946.

10. Imran AA, Salaria SM. Basaloid Squamous Cell Carcinoma of the Uterine Cervix. Inter J Pathol. 2012;10(2):88-90.

11. Kwon YS, Kim YM, Choi GW, et al. Pure basaloid squamous cell carcinoma of the uterine cervix: a case report. J Korean Med Sci. 2009;24(3):542-5. doi: 10.3346/jkms.2009.24.3.542

12. Tsai HJ, Liou B, Li MC. Rapid developing basaloid squamous cell carcinoma of the uterine cervix in a young adult Taiwanese. Malays J Pathol. 2013;35(2):177-80.

13. Martinez-Giron R, Martinez-Torre S, Mosquera-Martinez AJ. Basaloid squamous cell carcinoma of the uterine cervix: Cytological and histological features. Diagn Cytopathol. 2015;43(12):993-5. doi: 10.1002/dc.23364.

14. Terada T. Basaloid squamous cell carcinoma of esophagus expressing KIT: A case report with immunohistochemical analysis. Human Pathol. 2014;1(3):40-4.

15. Sampaio-Goes FC, Oliveira DT, Dorta RG, et al. Expression of PCNA, p53, Bax, and Bcl-X in oral poorly differentiated and basaloid squamous cell carcinoma: relationships with prognosis. Head Neck. 2005;27(11):982-9. doi: 10.1002/hed.20258.

16. Tsai HJ, Liou B, Li MC. Rapid developing basaloid squamous cell carcinoma of the uterine cervix in a young adult Taiwanese. Malays J Pathol. 2013;35(2):177-80.

\section{PEER REVIEW}

Not commissioned. Externally peer reviewed.

\section{CONFLICTS OF INTEREST}

The authors declare that they have no competing interests.

\section{FUNDING}

None

\section{PATIENT CONSENT}

The authors, Yordanov A, Slavchev S, Nanev V, Ivanova D, Ivanov $M$, Strashilov $S$, declare that: 
1. They have obtained written, informed consent for the publication of the details relating to the patient(s) in this report.

2. All possible steps have been taken to safeguard the identity of the patient(s).

3. This submission is compliant with the requirements of local research ethics committees. 